\title{
Expansion of ribosomally produced natural products: a nitrile hydratase- and Nif11-related precursor family
}

\author{
Daniel H Haft*1, Malay Kumar Basu¹ and Douglas A Mitchell ${ }^{* 2,3,4}$
}

\begin{abstract}
Background: A new family of natural products has been described in which cysteine, serine and threonine from ribosomally-produced peptides are converted to thiazoles, oxazoles and methyloxazoles, respectively. These metabolites and their biosynthetic gene clusters are now referred to as thiazole/oxazole-modified microcins (TOMM). As exemplified by microcin B17 and streptolysin S, TOMM precursors contain an N-terminal leader sequence and Cterminal core peptide. The leader sequence contains binding sites for the posttranslational modifying enzymes which subsequently act upon the core peptide. TOMM peptides are small and highly variable, frequently missed by genefinders and occasionally situated far from the thiazole/oxazole forming genes. Thus, locating a substrate for a particular TOMM pathway can be a challenging endeavor.

Results: Examination of candidate TOMM precursors has revealed a subclass with an uncharacteristically long leader sequence closely related to the enzyme nitrile hydratase. Members of this nitrile hydratase leader peptide (NHLP) family lack the metal-binding residues required for catalysis. Instead, NHLP sequences display the classic Gly-Gly cleavage motif and have C-terminal regions rich in heterocyclizable residues. The NHLP family exhibits a correlated species distribution and local clustering with an $A B C$ transport system. This study also provides evidence that a separate family, annotated as Nif1 1 nitrogen-fixing proteins, can serve as natural product precursors (N11P), but not always of the TOMM variety. Indeed, a number of cyanobacterial genomes show extensive N11P paralogous expansion, such as Nostoc, Prochlorococcus and Cyanothece, which replace the TOMM cluster with lanthionine biosynthetic machinery.

Conclusions: This study has united numerous TOMM gene clusters with their cognate substrates. These results suggest that two large protein families, the nitrile hydratases and Nif11, have been retailored for secondary metabolism. Precursors for TOMMs and lanthionine-containing peptides derived from larger proteins to which other functions are attributed, may be widespread. The functions of these natural products have yet to be elucidated, but it is probable that some will display valuable industrial or medical activities.
\end{abstract}

\section{Background}

Bacteriocins are polypeptide-based natural products of ribosomal origin, usually functioning as antibiotics toxic to rival strains or species of bacteria [1]. Peptide products resembling the bacteriocins in their size, precursor sequence, posttranslational modifications and co-cluster-

\footnotetext{
* Correspondence: DHaft@jcvi.org, douglasm@illinois.edu

1 The J Craig Venter Institute, 9704 Medical Center Drive, Rockville, MD 20850, USA

2 Department of Chemistry, University of Illinois at Urbana-Champaign,

Urbana, IL 61801, USA

Full list of author information is available at the end of the article
}

ing with maturation enzymes occasionally prove to have a signalling function or other non-antibiotic activity [2]. Collectively, these products represent a large reservoir of molecules with vast potential. Bacteriocin production and resistance mechanisms are, without question, major contributors to microbial ecology dynamics. Despite decades of research, including extensive work on low molecular weight bacteriocins (microcins), these processes are little understood. The small size and unusual amino acid composition of microcin precursor peptides hinder even the recognition of the open reading frame (ORF) as the coding region of a real gene [3,4]. Further- 
more, the low level of sequence similarity often found even among microcins of the same general class impedes identification of new microcins by sequence similarity. These arguments represent possible explanations for the reason why the study of ribosomally-produced peptide natural products has lagged behind that of the wellknown non-ribosomal peptide synthetase and polyketide synthase systems $[5,6]$.

A subset of microcins has been recently described in which the amino acid side chains of cysteine, serine and threonine from a ribosomally produced precursor undergo heterocyclization to generate a product with thiazole or (methyl)oxazole moieties. These include trichamide [7], the patellamides [8], goadsporin [9] and microcin B17 [10], among others. Building on these earlier studies, a research team led by Jack Dixon [4] described three types of proteins that represent a conserved biosynthetic machine for the formation of these heterocycle-containing metabolites across numerous microbial phyla. A zinc-tetrathiolate containing cyclodehydratase, flavin mononucleotide-dependent dehydrogenase and a docking scaffold protein are collectively responsible for the installation of thiazole and (methyl/ oxazole modifications to a peptide precursor (Figure 1A). In each case studied so far, the cyclodehydratase, dehydrogenase and docking scaffold proteins form a trimeric
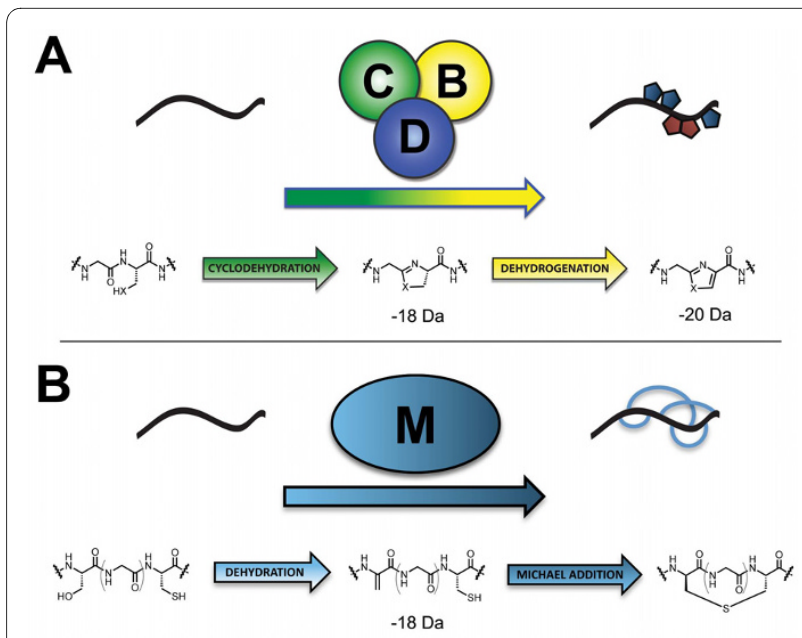

Figure 1 The biosynthesis and defining chemical features of TOMM and lanthionine-containing natural products. (A) Through the action of a trimeric 'BCD' complex, consisting of a cyclodehydratase (green), dehydrogenase (yellow) and docking/scaffolding protein (blue), thiazoles and (methyl/oxazoles are incorporated onto a peptidic scaffold (black). These heterocycles are synthesized from serine/threonine $(X=O)$ and cysteine $(X=S)$ residues of an inactive precursor peptide and yield a bioactive natural product. The chemical transformations carried out by the cyclodehydratase the dehydrogenase are shown, along with the corresponding mass change in Daltons. (B) A bifunctional synthase, LanM, catalyzes both the dehydration and Michael-type addition steps required to synthesize lanthionine crosslinks. complex (BCD) and serve to convert inactive, unstructured peptides into bioactive natural products $[4,11,12]$. The thiazole/oxazole heterocycles are biosynthesized over two distinct chemical transformations. The first is catalyzed by the cyclodehydratase (C), which converts Cys and Ser/Thr residues into the corresponding thiazoline and (methyl)oxazoline with loss of water from the amide backbone. In a second reaction, the dehydrogenase (B) removes two electrons and two protons to afford the aromatic thiazole and (methyl)oxazole $[10,13]$. The docking scaffold protein (D) appears to play a role in trimer assembly and the regulation of enzymatic activity. For each oxidized heterocycle formed, $20 \mathrm{Da}$ is lost from the parent peptide, which provides a convenient measure of product formation by mass spectrometry (Figure 1) $[4,8,14]$. This class of natural product has been termed the thiazole/oxazole-modified microcins (TOMMs).

In a simplified view, the purpose of the TOMM biosynthetic machinery is to recognize substrate and install structural constraints that restrict peptide bond rotation, thus endowing the modified peptide with a rigidified tertiary structure. By restricting conformational flexibility at the correct locations, the altered steric and electronic properties of the molecule, in conjunction with the physiochemical properties of the adjacent amino acids, lead to a specific biological activity. This type of rationale could also be extended to another family of post-translationally modified peptides, the lantibiotics, with the only major differences being the chemical composition (lanthionine containing) and biosynthetic installation of the structural constraints (Figure 1B) $[15,16]$.

Again, similar to the lanthionine-containing peptides (lantipeptides), TOMM precursor peptides are bipartite: they contain an $\mathrm{N}$-terminal leader sequence and a C-terminal 'core' peptide. The leader sequence has been shown in several cases to be critical to substrate recognition by the modifying enzymes, while the core peptide serves as a foundation upon which the active molecule is built [11,17-19]. Outside of the leader region, TOMM precursors tend to be rich in heterocyclizable residues (Cys, Ser, Thr) and also in Gly, whose minimal side chain reduces the energetic barrier required for cyclodehydration. Clues that support the interpretation of an ORF as a TOMM precursor include sequence similarity to previously identified TOMM precursors, a leader peptide cleavage motif, and a hypervariable $\mathrm{C}$-terminal core region rich in Gly, Cys, Ser and Thr [4,11]. Also aiding the identification of a TOMM cluster is the tendency of the modification enzymes to cluster with other genes necessary for the complete chemical maturation, export and immunity to the natural product $[4,20,21]$. Identification of genes encoding enzymes involved in lanthionine formation $[15,22,23]$, dehydroalanine production [9], peptide macrocyclization $[7,8,24,25]$ and thiazole/oxazole synthesis 
provide anchoring information for annotating post-translationally modified peptide biosynthetic clusters, such as the TOMMs and lantipeptides. Identification of other proteins (for example dehydrogenases, acetyltransferases, methyltransferases, proteases and transporters) in the local genomic region do not necessarily mark a biosynthetic cluster on their own but instead, help to define the extent and complexity of a proposed cluster [4].

Recent TOMM precursor identification by several groups $[3,8,24,26-29]$, including ours $[4,30]$, provide a growing number of short leader peptide sequences, a few of which show a moderate level of similarity with one another. However, many of the apparent TOMM biosynthetic systems have remained orphan systems, in that the thiazole/oxazole forming genes (encoding for the $\mathrm{BCD}$ synthetase complex, Figure 1A) could be detected but the TOMM precursors themselves could not be found. The current availability of well over 1000 complete bacterial and archaeal genomes permits the use of comparative genomics methods to locate the substrates for orphan TOMMs while simultaneously broadening the search for previously unknown families of post-translationally modified peptides. Our results illustrate the power of applying multiple informatics tools to the analysis of large numbers of fully sequenced genomes and suggest new opportunities to identifying secondary metabolite biosynthetic systems.

\section{Results and discussion}

Using a combination of informatics tools against a large number of sequenced genomes, we discovered several protein families that appear to represent an entirely new class of post-translationally modified peptide. The precursors have uncharacteristically long leader sequences and large paralogous family counts per genome. Analysis of the local genomic region predicts that these precursors will have variable chemical fates, including thiazole/ oxazole and lanthionine formation. These families, surprisingly, include one set of sequences with strong similarity to the alpha subunit of the enzyme nitrile hydratase (NHase) [31,32] while another set exhibits striking similarity to nitrogen-fixing proteins from cyanobacteria (Nif11) [33,34].

\section{Description of NHase-related leader microcin family}

One family of the newly discovered precursor peptides is described by TIGRFAMs model TIGR03793 (Table 1) and designated NHLP (nitrile hydratase-related leader peptides - as described below). In five diverse bacterial species, spanning several phyla, including firmicutes (Syntrophomonas wolfei subsp. wolfei str. Goettingen, Pelotomaculum thermopropionicum SI), proteobacteria (Stigmatella aurantiaca DW4/3-1, Syntrophus aciditrophicus SB [35]) and the chlorobi group (Chlorobium luteo- lum DSM 273), NHLP precursors are found adjacent to a cyclodehydratase-docking scaffold fusion protein (TIGR03882), a required component of TOMM biosynthesis [4]. The local genomic context of four of these biosynthetic clusters is illustrated in the upper portion of Figure 2. Additional species provide further supporting evidence for a link between NHLP and the cyclodehydratase-docking scaffold by co-occurrence within the same genome. Although not in close proximity to the cognate NHLP substrate, the cyclodehydratase-docking scaffold proteins from Microscilla marina ATCC 23134 (chlorobi group) and Methylobacterium sp. 4-46 (proteobacteria) represent two examples of this genetic organization. Akin to the NHLP system, previous informatics work has shown that the Bacillus anthracis and B. cereus TOMM precursors are encoded more than one megabase away from the modification cluster [30]. As with the NHLPs from M. marina and Methylobacterium, recognizing an orthologous cluster in B. licheniformis, in which all components were clustered, accelerated the identification of the precursors in B. anthracis and other members of the B. cereus group.

An unmistakable feature of the NHLP family is its close sequence similarity to the alpha subunit of NHase, which is described by TIGR01323 (Table 1 and Figure 3). Previously characterized NHases (EC 4.2.1.84) are composed of two subunits, alpha and beta, which together catalyze the general reaction shown below $[31,32]$.

$$
\mathrm{R}-\mathrm{C} \equiv \mathrm{N}+\mathrm{H}_{2} \mathrm{O} \rightarrow \mathrm{R}-\mathrm{C}(\mathrm{O}) \mathrm{NH}_{2}
$$

For over $90 \%$ of genomes containing a member of the NHase family (TIGR01323), that member occurs as the highest scoring sequence in the genome to a search using the fragment version (local-local scoring) Hidden Markov Model (HMM) of TIGR03793. Fragment model searches are preferred when match regions do not span the full length of the seed alignment or the target sequence. This is certainly the case when comparing sequences that have either a large insertion or deletion (indel) relative to each other. The median E-value for these HMM genome search results is $1 \mathrm{e}-7$, despite the short length (82 amino acids) of the TIGR03793 model. As these sequences are neither repetitive nor low in complexity in the regions covered by the HMM, the consistently low E-values for alignment between the two families predicts substantial sequence similarity between NHases and NHLPs. Furthermore, over three-quarters of the hits from TIGR03793 (fragment model) to NHases found two match segments, straddling a large indel region present in the alpha subunit of NHase, but not in TIGR03793 family sequences. The above described similarity and indel are clearly evident in the alignment [36] shown in Figure 3A. The sequences align convincingly over approximately 20 
Table 1: Description of TIGR models

\begin{tabular}{|c|c|c|c|}
\hline Accession & Colour* & Description & Abbreviation \\
\hline TIGR01323 & $\mathrm{N} / \mathrm{A}$ & Nitrile hydratase, alpha subunit & NHase \\
\hline TIGR03603 & $\mathrm{N} / \mathrm{A}$ & Cyclodehydratase (single ORF) & C \\
\hline TIGR03604 & Blue & Docking scaffold & $\mathrm{D}$ \\
\hline TIGR03882 & Green & Cyclodehydratase-docking (fused) & $C D$ \\
\hline TIGR03605 & Yellow & Dehydrogenase & B \\
\hline TIGR03793 & Black & NHase-related leader peptide & NHLP \\
\hline TIGR03795 & Dark gray & Burkholderia NHLP & NHLP-Burk \\
\hline TIGR03798 & Light gray & Nif11-related peptide & N11P \\
\hline TIGR03794 & Purple & HlyD-like, type I secretion & Trans-Fuse \\
\hline TIGR03796 & Red & $A B C$ transporter with peptidase & Trans-Cleave \\
\hline TIGR03797 & Red & $A B C$ transporter & Trans \\
\hline
\end{tabular}

residues $\mathrm{N}$-terminal, and 50 residues $\mathrm{C}$-terminal, to the region deleted from the NHLP family.

The deleted region includes the NHase CxxCSC motif, in which two of the three invariant cysteines are oxidatively modified - one to sulphenic acid, the other to sulphinic acid. Together, with a reduced cysteine thiol and amide nitrogen of serine, these moieties serve as ligands for the catalytic metal centre (Figure 3). NHase enzymes use either a non-heme iron or a non-corrinoid cobalt metal ion to activate water for hydrolyzing nitriles to amides [31,32,37] (Equation 1). As all NHLPs lack the entire active site region, they are suspected of being devoid of NHase enzymatic activity. Supporting this is a visual depiction of the segment of NHase missing in NHLP, provided by the X-ray crystal structure of the NHase from B. smithii (Figure 3B-3C) [38]. Another key difference between the NHase and NHLP families is the observation that the NHLPs harbour a classic leader peptide cleavage site (Gly-Gly), which occurs at the extreme C-terminal end of the region of similarity between the TIGR01323 and TIGR03793 models (Figure 3A). This motif also marks the end of sequence conservation among members within TIGR03793. Following the GlyGly motif is a hypervariable region, in which many sequences are rich in residues that are targeted by post- translational modifying enzymes (Cys, Ser, Thr, Figure 4). This composition suggests that the hypervariable region is the 'core peptide' and the homologous region comprises the leader sequence [18].

\section{Phylogenetic profiling studies show connection to a putative microcin export system}

We computationally evaluated the candidacy of the NHLP family as post-translationally modified peptide precursors by the method of partial phylogenetic profiling (PPP) [39], in which the profile serves as a query against an entire genome. A phylogenetic profile was constructed on the basis of whether or not each sequenced bacterial and archaeal genome carries a NHLP. Using PPP, all sequences in the genome were evaluated to determine which best match the profile. In a collection of 1450 complete, or nearly complete, microbial genomes, NHLPs occur in 14 species. Within these 14, each contain between one and 12 copies of NHLP in their respective genome (Figures 2, 3, 4). As shown in Table 2, the phylogenetic profile of these 14 NHLPs identified a three-gene $\mathrm{ABC}$ transport cluster as the only high-scoring protein family other than the NHLP precursor gene itself. The top hits from our PPP search include families TIGR03794 (Transfuse), TIGR03796 (TransCleave), and TIGR03797 

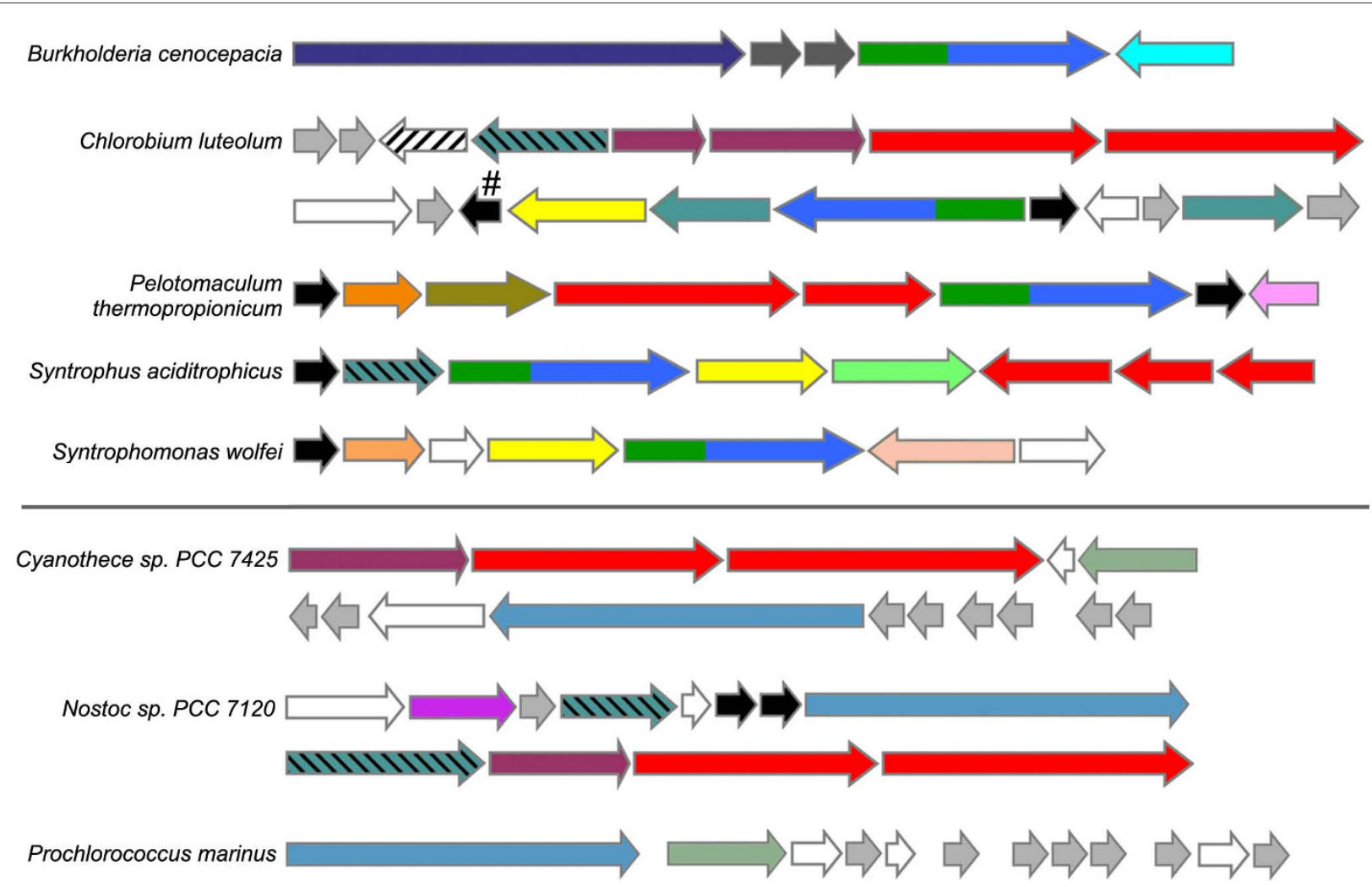

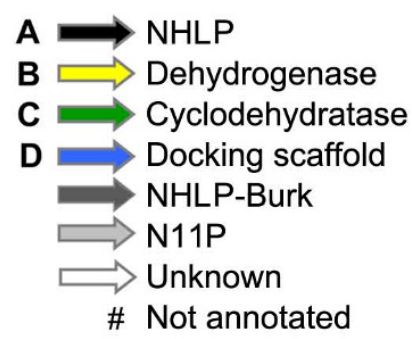

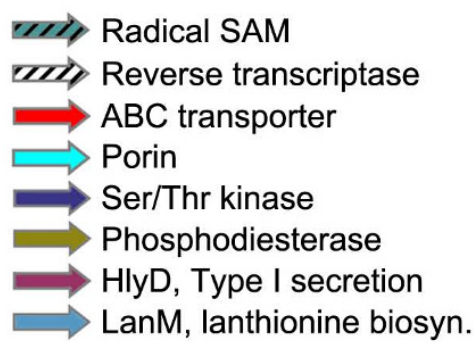

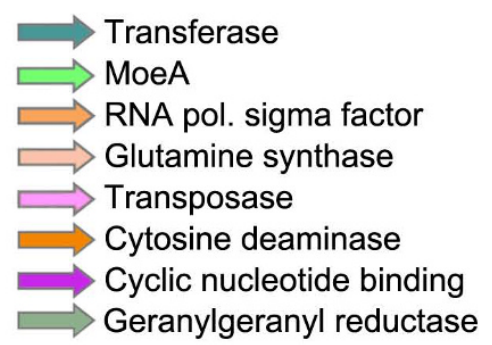

Figure 2 The genetic organization of TOMM and lanthionine biosynthetic clusters that utilize NHase- and Nif11-related precursor peptides. Genomic regions are shown from selected organisms in which the precursor peptides are clustered with the cognate modification enzymes. In most cases, a transport system is also visible in the local region. The TOMM precursors represented by Burkholeria cenocepacia (dark gray ORFs, NHLP-Burk) are accompanied by a large, Ser/Thr kinase. Highly similar clusters have been identified in Acidovorax avenae and Delftia acidovorans. In several species, precursors shown in black (NHLP) and light grey [Nif11-derived peptide (N11P)] may cluster with each other as well as with other modification and transporter genes. Note: only those precursors closest to the cyclodehydratase-docking scaffold protein or LanM-like lanthionine synthase are shown. For instance, Pelotomaculum thermopropionicum has 12 NHLPs (only two are shown) and seven N11P family precursors, while Cyanothece sp. PCC 7425 and P. marinus have 18 and 29 predicted N11P precursors, respectively (eight and seven are shown). Transport proteins, including those homologous to HlyD (type I secretion, purple) and ABC transporters (red), correspond to the transport genes detected by PPP.

(TransABC), which are also described in Table 1. A notable difference between TIGR03796 and TIGR03797 is that while both contain the adenosine triphosphate (ATP)-binding cassette domain and permease domain, the latter lacks the peptidase domain. TIGR03794 resembles the HlyD membrane fusion protein of type I secretion systems, suggesting a role in transport across the outer membrane. Natural product export, including unmodified and modified peptides, is often attributed to a nearby $\mathrm{ABC}$ transport system that combines a protease domain, permease domain and ATP-binding cassette, either as multiple ORFs or as a single polypeptide sequence $[40,41]$. The purpose of such a cassette is to simply cleave the leader peptide and export the mature product from the cell. NHLPs are adjacent to these transporter cassettes in a diverse array of bacterial species, including: Nostoc sp. PCC 7120* (cyanobacteria), Anabaena variabilis ATCC 29413 (cyanobacteria), M. marina 


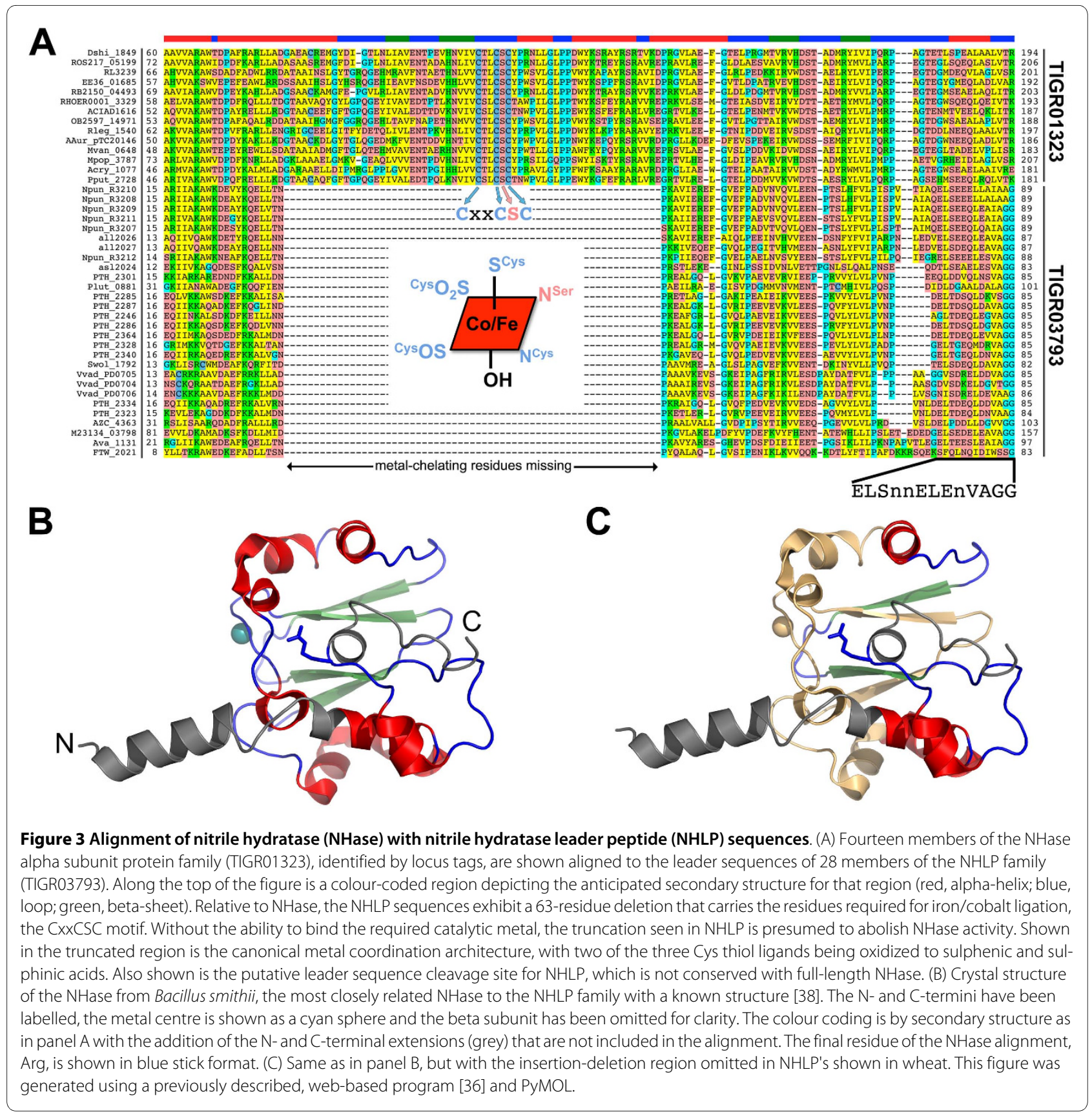

ATCC 23134 (chlorobi group), C. luteolum DSM 273* (chlorobi group), Victivallis vadensis ATCC str. BAA-548 (chlamydia group), and P. thermopropionicum SI* (firmicutes, " denotes a cluster shown in Figure 2). It is important to note that not all of putative biosynthetic clusters identified next to the $\mathrm{ABC}$ transporter genes are adjacent to TOMM machinery. In the case of Nostoc sp. PCC 7120, the NHLP and ABC transporter genes are adjacent to an enzyme resembling LanM, which is involved in lanthionine biosynthesis [16,42] (Figure 2). The findings from PPP strongly support our interpretation of NHLPs as posttranslationally modified peptide precursors and further argue that many, if not all, NHLP peptides will be subjected to leader peptide cleavage upon export.

The fact that correlation to a transport cassette emerges from PPP as a stronger relationship to the NHLP family, rather than any posttranslational tailoring enzyme, argues that the conservation in the leader peptide reflects a common mechanism of handling by the transport system (Table 2). The transport system appears to be providing more evolutionary pressure in order to maintain sequence similarity in this region than interaction with modification enzymes, which are usually considered to be highly specific $[11,18,19]$. This finding 
A

PTH 2286

$\mathrm{PTH} 2287$

PTH 2285

PTH_2334

$\mathrm{PTH} 2340$

PTH_2364

PTH 2328

PTH 2346

$\mathrm{PTH} 2314$

PTH_2356

$\mathrm{PTH} 2301$

PTH_2323

PTH_2286

PTH 2287

PTH_2285

$\mathrm{PTH} 2334$

PTH 2340

PTH 2364

PTH 2328

$\mathrm{PTH} 2346$

PTH 2314

PTH_2356

PTH 2301

PTH_2323

B

AZL a09850

AZL_a09840

AZL a09820

AZL_a09830

AZL a09860

AZL a 09790

AZL a09810

AzL_a09780

AZL_a09850

AZL_a09840

AZL a 09820

AZL a09830

AZL a09860

AZL a09790

AzL_a09810

AZL_a09780

AZL_a09850

AZL a 09840

AZL_a09820

AZL $a 09830$

AZL a09860

AZL_a09790

AZL_a09810

AZL_a09780
MGEAEKKPMTRREFEEQI IKKAQSDKEFKQDLVNNPKEALGKLGVRIPEEVEVKVVEESP MSDNEKKKMTRKEFEEQI IKKAQADKEFKQGLINDPKEALGKLGVRIPEEVEVKVLEESP MNOTENKPMTRREFEEOLVKKAWSDKEFKKALISAPRETLAGLGAKIPEAIE IKVVEESP MSENEKKPMTRKEFKEQIIKKAQADREFRKALVRNPKRAIGQLGVQFPEDVEVKVVEDSA MIESEKKPVTRKELKEOIIRKAOEDREFKKALVGNPKGAVEQLGVOLPEDVEVKVVEESA MSGNEKKPVSRKEFEEQIIMKAQSDEDFRKALMDNPKEALGQLGVRVPDEIEIKVFEESP MSENKKTSMTRKEFEGRIMKKVQTDGEFKKALTANPREALGRMGVOVPAE IEVKVVEESP MSENEMKPMTRQE IEEQI INKALSDKDFKEILLNNPKEAFGRLGVQLPAEVEIKVVEESP MDKG-NRTITRAELEKEIVKKAREDNDFKKALLDNPKEALGOLGVOVPEEVEVKVVEEPA MDKG-NRTITRAELEKEIVKKAREDNDFKKALLDNPKEALGQLGVQVPEEVEVKVVEEPA MDKG-NRTITRAELEKKIARKAREDNDFKKALLDNPREALGOLGVKVPAEVEVRVIEEPP MSGN-KKIITREELSKEVLEKAGDDKDFKKALMDNPKETLERLGVRVPEEVEIRVVEESP

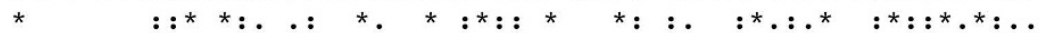

60 60 60 60 60 60 60 60 59 59 59 59

RVFYLVLPVNPDEL--TDSQLDGVAGGIC-FIAGEIDGKGACGIDTGHG-SLCFMKGWE-- 115 OVFYLVLPVNPDEL--TDSOLDAVAGGFCCFL----DYAPICGIDTDHSDOPCILLLSL-- 113 KVVYLVLPVNPDEL--TDSQLDKVSGGFC-IME---TTNETCGVDLEIV---CFMQLPNNF 112 GVVYLVLPVNLDEL--TDEOLDDVAGGE--SN--NCNHL-TGCTPAFRE----------- 102 EVVYLVLPVNPGEL--TGEQLDNVAGGTG-CS--DVYSF-PICVPTYHDNTVPAPKAG--- 112 QVLYLVLPLNPDEL--TDEQLEVVAGGAG-CSGQNVYSY-PICDPVYONTTERIPRAG--- 114 EVLYLVLPADPGEL--TGEQMDRVAGGGR-GYFRSCEGYGPWGCPIVACACY--------- 109 QVLYLVLPVNPAGL--TDEQLEGVAGGLE-LPGDWCLCHGRWNFNCWLLYRS--------- 109 RVVYLVLPVNPEEQLLVDEQLDSVAGGG--YNNFQVPPQCGVDCPAVQCPMRCETWMKI-- 116 RVLYLVLPVNPEEQLLNDEQLDSVAGGG--YNNFQVPPOCGVDCPAVRCPMRCETWMKI-- 116 RVVYLVLPVNPEEQ-LDDVQLNSVAGGGG-CNNFQGPPOARF---IVTGDKLIOGGIR--- 112 QVMYLVLPVNLDEL--TDEQLDNVAAGSCVIDSFICIGKCDS------FDPCRDYSL---- 108 $*^{*} * * * * \quad .{ }^{*}::^{*}: .^{*}$

MTRRDLEAKIVARAWSDDDFKAKFLADPKAMFEEHLGTKLPASLVMTAHEETADTIHFVI MSRRELEAKIVARAWSDDDFKAKFLADPKAMFEEHLGTKLPETLVMTAHEETPDTIHFVI MTRRDLEAKIVARAWSDDEFKAKFLADPKAMFEEHLGTKLPETLVMTAHEETADAIHFVI MTRRDLEAKIVARAWSDDDFKAKFLADPKAMFEEHLGTKLPETLVMTAHEETPDTIHFVI MTRRELEAKIVARAWSDDAFKAKFLADPKAMFEEHLGTKLPETLEITAHEETAEALHFVI MSRRELEAKIVARAWSDEDFKAKFLADPKAMFEEHLGTKLPETLVMTAHEETADALHFVI MTRRELEAKIVARAWSDEDFKAKFLADPKAMLEEHLGTRLPETLVIAAHEETADALHFVI MTRRELEAKIVARAWSDDTFKAKFLADPRAMFEEHLGTRFPEALTMTAHEETPDALHFVI

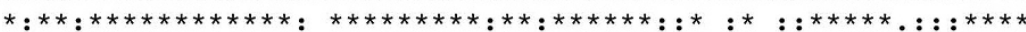

PAKPRIDLDELSDEDLEKVAGGVDIVTT--------ITVTAI ISAGVGGAAFSAVATVLA PAKPRIDLDELSDEDLEKVAGGVDFVTS---_----IIATAI ITASASALVTAPAAAILG PAKPQIDLDELSDEDLEKVAGGVDVS---------VTIFTAVMASALSAAATVAVSATAT PAKPQIDLDELSDEDLEKVAGGVDAITTAAIGTALFTLVTGLAASAVTAGVFTY IGGTMA PAKPRIDLDELSEEDLEKVAGGVDALAT------ALVTITISIASMVGTAASAGGVTYLT PAKPQIDLDELSDEDLEKVAGGVDVSLT-------VFVATVAITAGLSAGVAS-IGSLLG PAKPWSDLDELSDEDLEKVAGGVDVAEW---------MLRLRSSPPCPSLPSPPRLRQ PAKPQIDLDELSDEDLEKVAGGVDLVVT--------ACAVSIVATAAGMLATLSAMQISM 60 60 60 60 60 60 60 60

$* * * * * * * * * * * * * * * * * * * * * *$ :

AGGIRGVCAKW 123

TR-------KW 116

AGLI-----KW 117

ATHKG----SW 127

AKG-----AKW 120

GLAIP---RKW 120

Q---------- 110

YLDLKLNKKPW 123

Figure 4 Sequence alignment of nitrile hydratase leader peptides (NHLPs) from natural combinatorial biosynthetic clusters. ClustalW alignment [44] of NHLPs from a putative thiazole/oxazole-modified microcin cluster from (A)Pelotomaculum thermopropionicum SI (12 sequences) and (B) Azospirillum sp. B510 (eight sequences). Possible sites for thiazole formation are highlighted in cyan and sites of potential oxazole and methyloxazole formation are yellow. The locus tag is given to the left of the sequence and the amino acid position is given on the right. An asterisk implies an invariant residue, while the semicolon and period show positions that are highly and moderately related, respectively. Underlined red text indicates the putative leader peptide cleavage motif. 
Table 2: Partial phylogenetic profiling (PPP) results

\begin{tabular}{|c|c|c|c|c|c|}
\hline \multicolumn{6}{|c|}{ Chlorobium luteolum } \\
\hline 78186745 & 8 & 8 & 16 & -16.124 & NHLP \\
\hline 78186739 & 9 & 19 & 26 & -13.212 & Trans \\
\hline 78186738 & 9 & 22 & 29 & -12.492 & Trans-Cleave \\
\hline 78186736 & 8 & 16 & 17 & 12.045 & Trans-Fuse \\
\hline 78187852 & 10 & 95 & 123 & -7.475 & (PAS domain) \\
\hline \multicolumn{6}{|c|}{ Nostoc sp. PCC 7120} \\
\hline 17229519 & 9 & 9 & 23 & -18.140 & NHLP \\
\hline 17229518 & 11 & 21 & 38 & -16.662 & NHLP \\
\hline 17229516 & 8 & 8 & 23 & -16.124 & NHLP \\
\hline 17233313 & 10 & 20 & 26 & -14.927 & Trans \\
\hline 17229512 & 10 & 20 & 26 & -14.927 & Trans \\
\hline 17229513 & 11 & 33 & 42 & -13.969 & Trans-Cleave \\
\hline 17233311 & 10 & 25 & 31 & -13.698 & Trans-Cleave \\
\hline 17229514 & 9 & 24 & 33 & -12.080 & Trans-Fuse \\
\hline 17233314 & 9 & 26 & 35 & -11.709 & Trans-Fuse \\
\hline 17228094 & 7 & 19 & 27 & -9.451 & (S-layer homol.) \\
\hline \multicolumn{6}{|c|}{ Microscilla marina ATCC 23134} \\
\hline 123986279 & 9 & 16 & 23 & -14.108 & Trans \\
\hline 123988060 & 9 & 21 & 28 & -12.717 & Trans-Cleave \\
\hline 123988059 & 7 & 10 & 14 & -12.041 & Trans-Fuse \\
\hline 123992175 & 8 & 29 & 54 & -9.570 & (HAMP domain) \\
\hline \multicolumn{6}{|c|}{ Victivallis vadensis ATCC BAA-548 } \\
\hline 150259686 & 8 & 10 & 16 & -14.479 & Trans-Fuse \\
\hline 150259687 & 9 & 17 & 24 & -13.784 & Trans-Cleave \\
\hline 150259688 & 8 & 13 & 20 & -13.033 & Trans \\
\hline 150259679 & 6 & 6 & 15 & -12.093 & NHLP \\
\hline 150259681 & 5 & 6 & 8 & -9.303 & NHLP \\
\hline 150259680 & 4 & 4 & 6 & -8.062 & NHLP \\
\hline 150257768 & 10 & 88 & 119 & -7.798 & (GAF domain) \\
\hline
\end{tabular}

This table shows the results of PPP, where the profile contains 14 'YES' genomes having proteins recognized by TIGR03793, about 1\% of genomes and 1437 'NO' genomes. PPP scores each protein by selecting a BLAST score cutoff that gives the best possible fit between YES genomes in the profile and the set of genomes in the BLAST hits list, then scoring the fit at that depth. Columns, from left to right, are gi number, number of YES genomes encountered at the optimal depth, the total number of genomes at that depth, and the number of proteins at that depth (which can differ from the total number of genomes because several proteins may come from the same genome), the PPP score (a negative logarithm from the binomial distribution), and the protein family abbreviation. As PPP scores are not corrected for taxonomic relationships between species, scores are for comparison within each genome only and are shown down to the first noise hit. Results are shown in boldface except for noise hits. Note: Microscilla marina ATCC 23134 contains the nitrile hydratase leader peptide (NHLP) protein, 123988058 , which is not detected by PPP. This gene is found co-clustered with the transport proteins identified by PPP, as shown. 
suggests a mix-and-match evolutionary pattern for posttranslationally modified peptide biosynthesis and export systems, in which similarity in the leader peptide region provides only indirect evidence of which class of modification (thiazole/oxazole versus lanthionine) will occur. The broader species distribution of the newly defined putative export system, relative to the NHLP family through which they were detected, provides a unique opportunity to discover additional post-translationally modified peptides families in emerging and existing genomes.

\section{Core peptide hypervariability and natural combinatorial biosynthesis}

The hypervariability observed in NHLPs after the GlyGly motif is reminiscent of the variability in the core peptides of experimentally validated antimicrobial peptides, such as lichenicidin [42] and mersacidin [43]. An illustration of NHLP hypervariability is shown in Figure 4, where members of TIGR03793 are aligned using ClustalW [44]. Intriguingly, all 12 substrates shown in panel A are from the same organism, $P$. thermopropionicum $\mathrm{SI}$, a thermophilic, clostridia class bacterium [45], while all eight members shown in panel B are from Azospirillum sp. B510, a proteobacterial rice endophyte [46]. Within the local genomic context of the NHLPs from Azospirillum, there are a LanM-like lanthionine-forming enzyme (AZL_a09720) and an unfused docking scaffold protein (AZL_a09740). While these two genes are plasmid-borne, an additional copy of the unfused docking scaffold protein (AZL_022710) can be found on the chromosome, along with a cyclodehydratase encoded 3 ORFs away (AZL_022680). Therefore, it is not possible to determine the chemical fate of the Azospirillum peptide precursors at this time (Figure 4B). A more straightforward case is demonstrated with $P$. thermopropionicum, which contains one TOMM biosynthetic cassette and no discernable lanthionine-forming enzymes (Figure 2). This implies that the single $P$. thermopropionicum cyclodehydratase-docking scaffold fusion protein will process all of the NHLPs into 12 distinct natural products (Figure 4A). Supporting this is the observation that the leader peptide region is highly conserved. The leader sequence of posttranslationally modified peptides typically contains specific binding motifs recognized by the modifying enzymes $[11,17,18]$. This permits the selective modification of the desired peptide in a complex environment, such as the bacterial cytosol. Given that the P. thermopropionicum genome is relatively small (3.0 megabase, 2930 coding sequences), if this organism is to produce an extensive array of secondary metabolites, it must do so in a highly genome-efficient manner. This is in contrast to the much larger genome sizes of organisms renowned for secondary metabolism, such as Streptomyces coelicolor
(8.7 megabase, 7825 coding sequences) [47]. Such examples of natural combinatorial biosynthesis are becoming more frequent, as demonstrated with the cyanobactins by Eric Schmidt's group [24]. It appears that natural combinatorial biosynthesis could be an underappreciated trait of cyanobacteria, given that eight NHLPs were also identified in Nostoc punctiforme PCC 73102 (Figure 5 shows an alignment of six of these).

\section{NHLPs from Burkholderia}

Members of a second putative microcin precursor family, TIGR03795 (Table 1), occur near cyclodehydratase-docking scaffold fusion proteins in many proteobacteria of the Burkholderia order, including Delftia acidovorans SPH-1, two subspecies of Acidovorax avenae and multiple members within the genus Burkholderia: B. cenocepacia, $B$. ambifaria, B. pseudomallei, B. thailandensis, B. oklahomensis and B. mallei [48-50]. TIGR03795 family sequences occur exclusively as tandem gene pairs in the Burkholderia genus, suggesting these may form a twopeptide product, which are well-known (Figure 2) [41]. The tandem pairs in $D$. acidovorans and $A$. avenae are fused to yield a single polypeptide, further suggesting that the separate peptides from the Burkholderia genus function together. One member of each Burkholderia NHLP (NHLP-Burk) pair contains either Cys-Cys, or a single Cys, as the C-terminus (for example, Bcen_5137 and Bcen_5138). Members of this family were discovered as the top hits in their respective genomes to TIGR03793, suggesting a sequence relationship to the NHLP substrates described above. An alignment of NHase, NHLP and NHLP-Burk reveals a moderate level of sequence similarity. Relative to NHLP and NHase, NHLP-Burk contains an insert of about 15 amino acids $\mathrm{N}$-terminal to a Pro-Xaa-Xaa-Pro motif conserved amongst the three families. A major difference between NHLP and NHLPBurk lies in the leader peptide cleavage region (Table 3).

\section{Non-thiazole/oxazole modified NHLPs}

Besides the aforementioned case of Azospirillum, additional NHLP family members were found adjacent to a LanM-like lanthionine synthase, instead of a cyclodehydratase-docking fusion protein, in Nostoc sp. PCC 7120* and N. punctiforme PCC 73102 (" shown in Figure 2, lower panel). LanM is a bifunctional enzyme, responsible for both the dehydration of Ser/Thr residues to dehydroalanine/butyrine and, subsequently, intramolecular Michael-type addition of a Cys thiol to yield (methyl)lanthionines [15,23,51]. Aligning members of this family revealed that sequence conservation is strong over nearly 90 amino acids, and ends with a typical leader sequence cleavage motif, Gly-Gly (Figure 5) [18]. Reminiscent of the TOMM-type NHLPs, the sequence C-terminal of the Gly-Gly motif is short (average length 26) and highly vari- 


$\begin{array}{ll}\text { Npun_R3208 } & \text { MTQQEQAQTRQDIEARIIAK } \\ \text { Npun_R3210 } & \text { MSEQEQAQTRQDIEARIIAKA } \\ \text { Npun_R3209 } & \text { MSEQEQAQTRQDIEARIIAKA } \\ \text { Npun_R3207 } & \text { MSEQEQAQTRQDIEARIIAKA } \\ \text { Npun_R3211 } & \text { MSEQEQAQTRKNIEARIVAK } \\ \text { Npun_R3212 } & \text { MSEQ-QAQTRKDIESRIIAKA } \\ & \text { *: * *****: ** * : *** } \\ \text { Npun_R3208 } & \text { TSLHFVLPISPVAIAQELS } \\ \text { Npun_R3210 } & \text { TSLHFVLPISPVTIAQELS } \\ \text { Npun_R3209 } & \text { TSLHFVLPISPVAIAQELS } \\ \text { Npun_R3207 } & \text { TSLYFVLPLSPTAIMQELSE } \\ \text { Npun_R3211 } & \text { TSLYFVLPISPVAIAQELSE } \\ \text { Npun_R3212 } & \text { TSLYFVLPILPQIEGRELS } \\ & \text { ***:****: * } \\ \text { Npun_R3208 } & \text { LVTGASIGASSVHL- } 134 \\ \text { Npun_R3210 } & \text { LISGASIGASSVHL- } 131 \\ \text { Npun_R3209 } & \text { AITLVDTLKRLTK-- } 118 \\ \text { Npun_R3207 } & \text { LVSVSYLASHQIRR- } 122 \\ \text { Npun_R3211 } & \text { ILPIRHSLVKTLR-- 118 } \\ \text { Npun_R3212 } & \text { FTGDIVKATKKLTKK 117 }\end{array}$

Figure 5 Sequence alignment of nitrile hydratase leader peptides (NHLPs) from Nostdoc punctiforme PCC 73102. Shown is a ClustalW alignment of six selected NHLP substrates. N. punctiforme PCC 73102 has at least 16 total substrates, half of which are NHLP and the other half N11P. The coloring scheme and notation are identical to Figure 4.

able. Although not depicted in Figure 5, over $60 \%$ of the NHLPs adjacent to LanM-like proteins contain Cys in their core peptide, meaning that these substrates are capable of containing lanthionine crosslinks. NonTOMM NHLPs lacking Cys in the core peptide will presumably remain at the dehydrated state, unless new tailoring modifications are discovered that further process these groups.

Post-translationally modified microcins derived from a putative nitrogen-fixing protein

A third protein family, TIGR03798, reprises many of the features of NHLP (Table 1) but are only found in bacteria known to fix nitrogen, with most members also being photosynthetic. TIGR03798 comprises a subset of the Nif11 family (PF07862), which is heavily skewed to the cyanobacteria. Nif11 proteins have no known function [33]. TIGR03798 family members, such as NHLP, occur in fairly large paralogous families. From this point on, we will refer to TIGR03798 as Nif11-derived peptides (N11P). N11P substrates are adjacent to the cyclodehydratase-docking scaffold fusion protein in C. luteolum (Figure 2) and nearby in P. thermopropionicum. In many cases, N11Ps are adjacent to $\mathrm{ABC}$ transport clusters (as defined by TIGR03794, TIGR03796, and TIGR03797) in

Table 3: Motif relationships in nitrile hydratase leader peptide (NHLP) and Nif11-related protein (N11P) leader sequences to nitrile hydratase (NHase)

\begin{tabular}{|c|c|c|c|c|c|}
\hline Accession & Description & Motif 1 & Motif 2 & Leader & Suffix \\
\hline TIGR01847 & Gram-positive leader & $\mathrm{N} / \mathrm{A}$ & ELSEKELAQ\|GG & 23 & 41 \\
\hline TIGR03898 & lichenicidin leader & IIRAWKDPEYRASLSSE & ELSDEELESITGG & 47 & 30 \\
\hline TIGR03798 & N11P & $\mathrm{N} / \mathrm{A}$ & ELSDEELEAVAGG & 69 & 23 \\
\hline TIGR03793 & NHLP & IKKAWSDEEFKQALLNN & ELSDEQLDAVAGG & 87 & 27 \\
\hline TIGR03795 & NHLP-Burk & IALAWHDPEFRDELLAD & $\mathrm{N} / \mathrm{A}$ & 108 & 11 \\
\hline TIGR01323 & NHase & VAKAWVDPEFKARLLKD & GLSEEQLAALVTR & 193 & 16 \\
\hline
\end{tabular}

Sequence similarities and motif positions in NHase alpha subunit and putative leader sequences. Residues shared by at least $70 \%$ of the calculated consensus sequences are shown in boldface. Leader peptide length is taken as the position of the C-terminal end of motif 2 , averaged after the shortest $10 \%$ and longest $10 \%$ removed of each family are removed as outliers and possible gene call errors. The similarity of NHLP to N11P in motif 2 suggests intragenic recombination. 
C. luteolum, Synechococcus sp. WH 7803, C. phaeobacteroides, Desulfitobacterium hafniense and Eggerthella lenta DSM 2243, among others. Additional N11P members occur adjacent to LanM-like lanthionine-forming enzymes in numerous species of cyanobacteria, including N. punctiforme PCC 73102, Nostoc sp. PCC 7120, Prochloroccocus marinus sp. MIT9313, and Cyanothece sp. PCC 7425 (Figure 2) [52]. In the case of N. punctiforme PCC 73102, which also possess eight NHLP type substrates (Figure 5), four LanM-like enzymes (Npun_R3205, Npun_R3312, Npun_AF076, and Npun_F5047) are expected to process an additional eight N11P substrates for a total of 16 unique post-translationally modified microcins.

Occurrence in the same genome with a LanM homolog, although not necessarily clustered, is a feature of N11P family proteins from Synechococcus sp. RS9916 and Sinorhizobium medicae WSM419. Like NHLP and NHLP-Burk, N11P sequences also have a classic leader peptide cleavage motif, usually Gly-Gly, which marks the end of family-wide similarity and the beginning of a lowcomplexity region rich in Cys, Gly and Ser. As depicted by a logo diagram (Figure 6) [53], the regions leading up to the Gly-Gly motif in NHLPs and N11Ps are quite similar to that of the leader peptides of family TIGR01847 (Table 3 ), which includes plantaricin A and lactococcin B $[41,54,55]$, two well-known, class II bacteriocins (unmodified microcins).

\section{Interfamily relationships of NHLP, NHLP-Burk and N11P}

None of the three types of transport genes (Trans, TransCleave, Trans-Fuse) identified by PPP have a close homolog in species with NHLP-Burk family members. This implies that the export mechanism, if any, must differ. The occurrence of NHLP-Burk members in pairs, fused in some genomes, suggests a two-chain structure. If exported, these metabolites will likely require a different transport mechanism. The NHLP and NHLP-Burk families do exhibit extensive sequence similarity (motif 1 , Table 3), although not in the putative leader peptide cleavage region (motif 2, Table 3). N11P does not show clear evidence of direct similarity to the NHase alpha subunit, as evidenced by extremely poor $E$-values $(>1.0)$ when querying all NHases against any N11P family member. Nevertheless, N11P does exhibit regions of local sequence similarity to NHLP (motif 2, Table 3). To validate the similarity, TIGR03793 (NHLP) and TIGR03798 (N11P) were each searched against species that were known to only contain members of the other family. For instance, a TIGR03793 search against the draft genome of Synechococcus sp. RS9916, which contains 31 N11P sequences but no identifiable NHLP sequences, revealed that 19 of the 24 nearest matches are actually members of the N11P family. A similar search performed on Cyanoth-
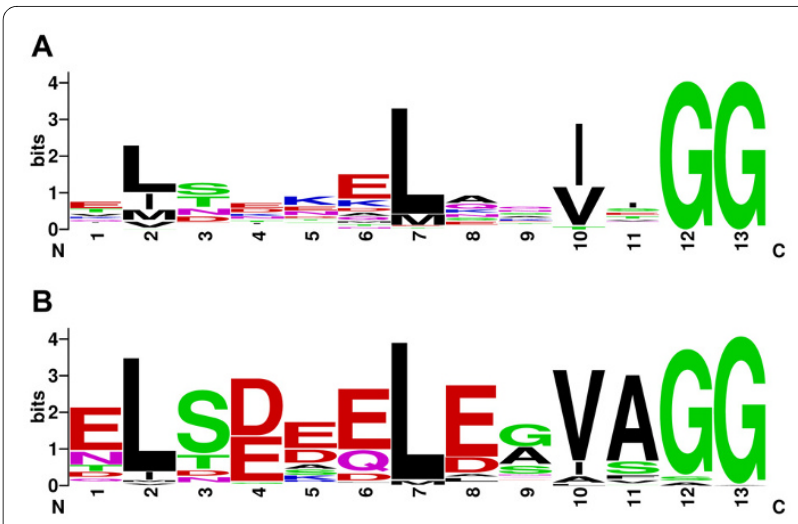

Figure 6 Sequence logo comparison of classical Gram-positive bacteriocin and nitrile hydratase leader peptides (NHLP)/Nif11derived peptides (N11Ps). (A) Logo depiction of TIGR01847, which is representative of the sequence found near the peptide cleavage site of Gram-positive bacteriocins. (B) Logo for the NHLP and N11P families taken together. In addition to the classic Gly-Gly cleavage motif (positions 12-13), the two logos show an abundance of acidic residues at positions 1, 4 and 6 and a significant preference for Leu at position 2 and 7, Ser/Thr at position 3, and either Val/Leu at position 10. This figure was generated online using a published algorithm [53].

ece sp. PCC 7425 returns 13 members of N11P as the top scoring 15 sequences. Such searches also work with members of the NHLP-Burk family. To illustrate, a search with N11P against Burkholderia returns a member of NHLP-Burk as the top hit. This cross-specificity, although occurring at the 'noise' level, which is well below the manually set trusted cutoff of each model, reflects two regions of significant similarity between the three precursor families. The more striking region, designated motif 2 (Table 3), is the 13 amino acid stretch leading to the Gly-Gly motif, similar to the leader peptide cleavage region of model TIGR01847. In more classic lantibiotics, such as lacticin 481 , similarity of this region to class II bacteriocins has been previously noted [56]. Another region also shows strong sequence similarity between NHLP, NHLP-Burk and N11P. This region, designated motif 1 , corresponds to the conserved sequence in the NHase alpha subunit $\mathrm{N}$-terminal to the active site Cys residues (Figure 3). These results, in conjunction with the noted paralogous duplication, are almost certainly the result of intragenic recombination [57].

\section{Conclusion}

The proposed precursor families described in this report dramatically expand the current repertoire of ribosomally produced natural products. This revision includes hundreds of peptides that exhibit (i) long leader peptide regions, (ii) similarity to proteins and enzymes assigned to other functions and (iii) locations distant to the genomic regions used to encode their modification and export genes. Microcins recognized by TIGR01847 have 
leader peptides predicted to end at an average length of 24 amino acids. However, the corresponding Gly-Gly motifs in the new discovered families presented here end at an average position of 83 and 70 for NHLP and N11P, respectively. NHLPs demonstrate significant sequence similarity to the alpha subunit of NHase, suggesting strongly that they share a common ancestor. NHase is an enzyme with a function unrelated to microcin production and, thus, a broader implication of our findings is that a small protein cannot be automatically excluded from classification as a precursor to a natural product, even if it is homologous to a protein with a known function.

The success of the approach employed here implies that a parallel strategy could prove useful to unravelling other natural product biosynthetic pathways. Possible applications are found in eukaryotic systems, such as in plants, where complex natural product pathways exist, but the requisite genes are not clustered. Clearly, the discovery of new ribosomally produced natural products is far from complete. Even within the families reported here, some members of NHLP and N11P occur in species without identified TOMM or lanthionine-forming enzymes. Furthermore, numerous TOMM clusters remain orphans, with candidate precursors yet to be identified. New tools and concepts, such as those described here, will be of importance in further defining the chemical genetic scope of ribosomally produced natural products.

Note: While this manuscript was under review, an independent report was published describing the in vitro reconstitution and in vivo production of numerous N11Pderived natural products from $P$. marinus sp. MIT9313 [58]. This finding strongly suggests that our informaticsbased predictions will hold up to further experimental validation.

\section{Methods \\ General}

Multiple sequence alignments were generated using MUSCLE [36] or ClustalW [44], inspected, and refined manually. Refinements included trimming, removal of truncated and other defective sequences, recruitment of additional sequences, and realignment as necessary to create representative seed alignments. Completed seed alignments were used to construct HMMs. The resulting new HMM-based protein family definitions, described in this work, were deposited in the TIGRFAMs database $[59,60]$. All HMM accessions refer to TIGRFAMs release 9.0 or Pfam release 22 [61].

In order to model regions of local sequence similarity between different protein families, multiple alignments were first generated, trimmed and used to train HMMs for searches to gather additional candidate sequences through an iterated, manual process. HMM construction was performed with the Logical Depth 1.5.4 package soft- ware-accelerated emulation of HMMER 2.3. The resulting motif models, of lengths 17 and 13, were searched against the individual families TIGR01323, TIGR03793, TIGR03795, TIGR03798 and the set of 20 proteins that resulted from PSI-BLAST [62]. The PSI-BLAST iterations were carried out to convergence, starting from the predicted 49-residue leader peptide of a hypothetical lanthionine-containing peptide, gi|228993822 from $B$. pseudomycoides SDM 12442), using composition-based statistics and an $E$-value of 0.5 . This search strategy provides a working definition for the set of lichenicidinrelated bacteriocins homologous in the leader peptide, rather than the core peptide. All non-identical sequences scoring above 0 bits to the respective motif HMMs were aligned to the HMM, resulting in gapless alignments. For each of these, a final HMM was built in order to emit a consensus sequence.

\section{Description of TIGR (The Institute for Genome Research) models to locate biosynthetic genes}

Previous work has identified many cyclodehydratase, dehydrogenase and docking scaffold genes [4,24,27]. In alpha/delta-proteobacteria, actinobacteria, cyanobacteria, and chlorobi type bacteria, the cyclodehydratase and docking scaffolds tend to be found encoded as a single ORF, while other taxa usually produce separate protein products [4]. TIGR03604 describes the docking protein in both fused and unfused cases. TIGR03603 identifies cyclodehydratases that occur as separate genes adjacent to the docking scaffold gene, but a new model, TIGR03882, had to be developed to reliably identify the cyclodehydratase region of the enzymes fused to the docking scaffold. All regions identified by TIGR03882 are fused to a docking scaffold domain, and iteration by PSIBLAST demonstrates, as expected, weak similarity to a set of known proteins: ThiF of thiamine biosynthesis [63,64], MoeB of molybdopterin biosynthesis [65], ubiquitin E1 conjugating enzymes and the cyclodehydratases identified by TIGR03603. The sequence similarity between post-translationally modified microcins and thiamine/molybdopterin biosynthetic proteins have been previously documented [66]. MccB, an enzyme involved in microcin $\mathrm{C} 7$ biosynthesis, also shares considerable similarity to ThiF/MoeB/E1. The Walsh and Schulman groups have recently characterized the MccB protein, confirming the earlier report [67,68]. TIGR03882 recognizes the cyclodehydratase domains of the TriA protein for trichamide biosynthesis in Trichodesmium erythraeum [7] and the PatD protein of patellamide biosynthesis in Prochloron didemni [8]. The corresponding cyanobactin-type TOMM precursors of these systems are recognized by TIGR03678 $[67,68]$. Succinct descriptions of all TIGR models of interest to this study are tabulated in Tables 1 and 3. 
An examination of the genes in the vicinity of orphan cyclodehydratase-docking scaffold fusion proteins revealed no examples of short peptides qualitatively similar to those previously presented by Lee and Mitchell et al. [4]. Previously identified peptides featured leader sequences of approximately 25 amino acids, followed by regions of very low complexity, often of a repetitive nature, and highly enriched in cysteine, serine and threonine. However, our latest survey identified somewhat larger peptides nearby which warranted further investigation as potential TOMM precursors. For each family, founding members were aligned in order to build HMMs and search results were manually inspected in order to set cutoffs for each family. The three families, now represented by TIGRFAMs models TIGR03793, TIGR03795 and TIGR03798 (Table 1) serve as the basis for this report.

\section{Partial phylogenetic profiling}

Selected TIGRFAM models were searched against a collection of 1450 complete or nearly complete bacterial and archaeal genomes. All genomes with at least one protein scoring above the trusted cutoff of the model were assigned the value 1 ('YES') in the phylogenetic profile built to represent that model, while all other genomes were assigned the value 0 ('NO'). By PPP [39], the phylogenetic profile serves as a query to find which genes in a genome may belong to protein families that can best match that profile. PPP produces a score for each protein in a genome by exploring increasing depths in the list of best BLAST matches to that protein. PPP also records the growing set of genomes from which those protein matches originate. At each depth, PPP counts the numbers of genomes agreeing ('YES') and disagreeing ('NO') with the query profile and uses the binomial distribution to score the odds of obtaining at least that many agreements. The overall score for each protein is based on a depth for which the negative $\log _{10}$ of the score is maximized, corresponding to an optimum for the working size of a candidate protein family. Each phylogenetic profile was used to query all genomes assigned as YES in the profile. Top-scoring proteins were identified for further analysis. In essence, PPP makes it possible to detect a protein family that matches a query profile, even if that family has never previously been defined.

\section{List of abbreviations}

ABC: ATP-binding cassette; ATP: adenosine triphosphate; HMM: hidden Markov model; indel: insertiondeletion; N11P: Nif11-derived peptide; NHase: nitrile hydratase; NHLP: nitrile hydratase leader peptide; NHLP-Burk: Burkholderia type TOMM substrate family; Nif11: nitrogen fixation protein of unknown function; ORF: open reading frame; PPP: partial phylogenetic pro- filing; TIGR: The Institute for Genomic Research; TOMM: thiazole/oxazole-modified microcin.

\section{Authors' contributions}

$\mathrm{DHH}$ conceived the study and constructed the TIGRFAM models. DAM participated in the model validation and expanded the scope of the study. MKB developed improved software tools for detecting protein family relationships. $\mathrm{DHH}$ and DAM analysed and interpreted the data. $\mathrm{DHH}$ and DAM wrote the paper. All authors read and approved the final manuscript.

\section{Acknowledgements}

The authors wish to thank Eric Eisenstadt and members of the Mitchell Laboratory for the critical review of the manuscript. This work was supported by grants 1 R01 HGO04881, HHSN266200400038C and by institutional funds provided by the Department of Chemistry at the University of Illinois.

\section{Author Details}

1The J Craig Venter Institute, 9704 Medical Center Drive, Rockville, MD 20850, USA, ${ }^{2}$ Department of Chemistry, University of Illinois at Urbana-Champaign, Urbana, IL 61801, USA, ${ }^{3}$ Department of Microbiology, University of Illinois at Urbana-Champaign, Urbana, IL 61801, USA and 4Institute for Genomic Biology, University of Illinois at Urbana-Champaign, Urbana, IL 61801, USA

Received: 21 March 2010 Accepted: 25 May 2010

Published: 25 May 2010

\section{References}

1. Cotter PD, Hill C, Ross RP: Bacteriocins: developing innate immunity for food. Nat Rev Microbiol 2005, 3:777-788.

2. Kodani S, Hudson ME, Durrant MC, Buttner MJ, Nodwell JR, Willey JM: The SapB morphogen is a lantibiotic-like peptide derived from the product of the developmental gene ramS in Streptomyces coelicolor. Proc Natl Acad Sci USA 2004, 101:11448-11453.

3. Cotter PD, Draper LA, Lawton EM, Daly KM, Groeger DS, Casey PG, Ross RP, Hill C: Listeriolysin S, a novel peptide haemolysin associated with a subset of lineage I Listeria monocytogenes. PLoS Pathog 2008, 4:e1000144.

4. Lee SW, Mitchell DA, Markley AL, Hensler ME, Gonzalez D, Wohlrab A, Dorrestein PC, Nizet V, Dixon JE: Discovery of a widely distributed toxin biosynthetic gene cluster. Proc Natl Acad Sci USA 2008, 105:5879-5884.

5. Cane DE, Walsh CT, Khosla C: Harnessing the biosynthetic code: combinations, permutations, and mutations. Science 1998, 282:63-68.

6. Cane DE, Walsh CT: The parallel and convergent universes of polyketide synthases and nonribosomal peptide synthetases. Chem Biol 1999, 6:R319-325.

7. Sudek S, Haygood MG, Youssef DT, Schmidt EW: Structure of trichamide, a cyclic peptide from the bloom-forming cyanobacterium Trichodesmium erythraeum, predicted from the genome sequence. Appl Environ Microbiol 2006, 72:4382-4387.

8. Schmidt EW, Nelson JT, Rasko DA, Sudek S, Eisen JA, Haygood MG, Ravel J: Patellamide $A$ and $C$ biosynthesis by a microcin-like pathway in Prochloron didemni, the cyanobacterial symbiont of Lissoclinum patella. Proc Natl Acad Sci USA 2005, 102:7315-7320.

9. Onaka H, Nakaho M, Hayashi $K$, Igarashi Y, Furumai T: Cloning and characterization of the goadsporin biosynthetic gene cluster from Streptomyces sp. TP-A0584. Microbiology 2005, 151:3923-3933.

10. Li YM, Milne JC, Madison LL, Kolter R, Walsh CT: From peptide precursors to oxazole and thiazole-containing peptide antibiotics: microcin B17 synthase. Science 1996, 274:1188-1193.

11. Mitchell DA, Lee SW, Pence MA, Markley AL, Limm JD, Nizet V, Dixon JE: Structural and functional dissection of the heterocyclic peptide cytotoxin streptolysin S. J Biol Chem 2009, 284:13004-13012.

12. Roy RS, Gehring AM, Milne JC, Belshaw PJ, Walsh CT: Thiazole and oxazole peptides: biosynthesis and molecular machinery. Nat Prod Rep 1999, 16:249-263.

13. Milne JC, Roy RS, Eliot AC, Kelleher NL, Wokhlu A, Nickels B, Walsh CT: Cofactor requirements and reconstitution of microcin $B 17$ synthetase: a multienzyme complex that catalyzes the formation of oxazoles and thiazoles in the antibiotic microcin B17. Biochemistry 1999, 38:4768-4781 
14. Kelleher NL, Hendrickson CL, Walsh CT: Posttranslational heterocyclization of cysteine and serine residues in the antibiotic microcin B17: distributivity and directionality. Biochemistry 1999, 38:15623-15630.

15. Willey JM, Donk WA van der: Lantibiotics: peptides of diverse structure and function. Annu Rev Microbiol 2007, 61:477-501.

16. Xie L, Miller LM, Chatterjee C, Averin O, Kelleher NL, Donk WA van der: Lacticin 481: in vitro reconstitution of lantibiotic synthetase activity. Science 2004, 303:679-681.

17. Madison LL, Vivas El, Li YM, Walsh CT, Kolter R: The leader peptide is essential for the post-translational modification of the DNA-gyrase inhibitor microcin B17. Mol Microbiol 1997, 23:161-168.

18. Oman TJ, Donk WA van der: Follow the leader: the use of leader peptides to guide natural product biosynthesis. Nat Chem Biol 2010, 6:9-18.

19. Roy RS, Kim S, Baleja JD, Walsh CT: Role of the microcin B17 propeptide in substrate recognition: solution structure and mutational analysis of McbA1-26. Chem Biol 1998, 5:217-228.

20. Millan San $J$, Kolter R, Moreno F: Plasmid genes required for microcin B17 production. J Bacteriol 1985, 163:1016-1020.

21. Nizet V, Beall B, Bast DJ, Datta V, Kilburn L, Low DE, De Azavedo JC: Genetic locus for streptolysin S production by group A streptococcus. Infect Immun 2000, 68:4245-4254.

22. de Vos WM, Kuipers OP, Meer JR van der, Siezen RJ: Maturation pathway of nisin and other lantibiotics: post-translationally modified antimicrobial peptides exported by gram-positive bacteria. Mol Microbiol 1995, 17:427-437.

23. Li B, Yu JP, Brunzelle JS, Moll GN, Donk WA van der, Nair SK: Structure and mechanism of the lantibiotic cyclase involved in nisin biosynthesis. Science 2006, 311:1464-1467.

24. Donia MS, Hathaway BJ, Sudek S, Haygood MG, Rosovitz MJ, Ravel J, Schmidt EW: Natural combinatorial peptide libraries in cyanobacterial symbionts of marine ascidians. Nat Chem Biol 2006, 2:729-735.

25. Mclntosh JA, Donia MS, Schmidt EW: Ribosomal peptide natural products: bridging the ribosomal and nonribosomal worlds. Nat Prod Rep 2009, 26:537-559.

26. Kelly WL, Pan L, Li C: Thiostrepton biosynthesis: prototype for a new family of bacteriocins. J Am Chem Soc 2009, 131:4327-4334.

27. Brown Wieland LC, Acker MG, Clardy J, Walsh CT, Fischbach MA: Thirteen posttranslational modifications convert a 14-residue peptide into the antibiotic thiocillin. Proc Nat/ Acad Sci USA 2009, 106:2549-2553.

28. Liao R, Duan L, Lei C, Pan H, Ding Y, Zhang Q, Chen D, Shen B, Yu Y, Liu W: Thiopeptide biosynthesis featuring ribosomally synthesized precursor peptides and conserved posttranslational modifications. Chem Biol 2009, 16:141-147.

29. Morris RP, Leeds JA, Naegeli HU, Oberer L, Memmert K, Weber E, LaMarche MJ, Parker CN, Burrer N, Esterow S: Ribosomally synthesized thiopeptide antibiotics targeting elongation factor Tu. J Am Chem Soc 2009, 131:5946-5955.

30. Haft DH: A strain-variable bacteriocin in Bacillus anthracis and Bacillus cereus with repeated Cys-Xaa-Xaa motifs. Biol Direct 2009, 4:15.

31. Harrop TC, Mascharak PK: Fe(III) and Co(III) centers with carboxamido nitrogen and modified sulfur coordination: lessons learned from nitrile hydratase. Acc Chem Res 2004, 37:253-260

32. Kobayashi M, Shimizu S: Metalloenzyme nitrile hydratase: structure, regulation and application to biotechnology. Nat Biotechnol 1998 16:733-736

33. Jacobson MR, Brigle KE, Bennett LT, Setterquist RA, Wilson MS, Cash VL, Beynon J, Newton WE, Dean DR: Physical and genetic map of the major nif gene cluster from Azotobacter vinelandii. J Bacteriol 1989, 171:1017-1027.

34. Kaneko T, Nakamura Y, Wolk CP, Kuritz T, Sasamoto S, Watanabe A, Iriguchi M, Ishikawa A, Kawashima K, Kimura T: Complete genomic sequence of the filamentous nitrogen-fixing cyanobacterium Anabaena sp. strain PCC 7120. DNA Res 2001, 8:205-213. 227-253

35. McInerney MJ, Rohlin L, Mouttaki H, Kim U, Krupp RS, Rios-Hernandez L, Sieber J, Struchtemeyer CG, Bhattacharyya A, Campbell JW, Gunsalus RP. The genome of Syntrophus aciditrophicus: life at the thermodynamic limit of microbial growth. Proc Natl Acad Sci USA 2007, 104:7600-7605.

36. Edgar RC: MUSCLE: multiple sequence alignment with high accuracy and high throughput. Nucleic Acids Res 2004, 32:1792-1797.
37. Banerjee A, Sharma R, Banerjee UC: The nitrile-degrading enzymes: current status and future prospects. App/Microbiol Biotechnol 2002, 60:33-44.

38. Hourai S, Miki M, Takashima Y, Mitsuda S, Yanagi K: Crystal structure of nitrile hydratase from a thermophilic Bacillus smithii. Biochem Biophys Res Commun 2003, 312:340-345.

39. Haft DH, Paulsen IT, Ward N, Selengut JD: Exopolysaccharide-associated protein sorting in environmental organisms: the PEP-CTERM/EpsH system. Application of a novel phylogenetic profiling heuristic. $B M C$ Biol 2006, 4:29.

40. Datta V, Myskowski SM, Kwinn LA, Chiem DN, Varki N, Kansal RG, Kotb M, Nizet $V$ : Mutational analysis of the group A streptococcal operon encoding streptolysin $\mathrm{S}$ and its virulence role in invasive infection. $\mathrm{Mol}$ Microbiol 2005, 56:681-695.

41. Oppegard C, Rogne P, Emanuelsen L, Kristiansen PE, Fimland G, NissenMeyer J: The two-peptide class II bacteriocins: structure, production, and mode of action. J Mol Microbiol Biotechnol 2007, 13:210-219.

42. Begley M, Cotter PD, Hill C, Ross RP: Identification of a novel two-peptide lantibiotic, lichenicidin, following rational genome mining for LanM proteins. Appl Environ Microbiol 2009, 75:5451-5460.

43. Appleyard AN, Choi S, Read DM, Lightfoot A, Boakes S, Hoffmann A, Chopra I, Bierbaum G, Rudd BA, Dawson MJ, Cortes J: Dissecting structural and functional diversity of the lantibiotic mersacidin. Chem Biol 2009, 16:490-498.

44. Thompson JD, Gibson TJ, Higgins DG: Multiple sequence alignment using ClustalW and ClustalX. Curr Protoc Bioinformatics 2002, Chapter 2:Unit 23.

45. Kosaka T, Kato S, Shimoyama T, Ishii S, Abe T, Watanabe K: The genome of Pelotomaculum thermopropionicum reveals niche-associated evolution in anaerobic microbiota. Genome Res 2008, 18:442-448.

46. Kaneko T, Minamisawa K, Isawa T, Nakatsukasa H, Mitsui H, Kawaharada Y, Nakamura Y, Watanabe A, Kawashima K, Ono A: Complete genomic structure of the cultivated rice endophyte Azospirillum sp. B510. DNA Res 2010, 17:37-50.

47. Bentley SD, Chater KF, Cerdeno-Tarraga AM, Challis GL, Thomson NR, James KD, Harris DE, Quail MA, Kieser H, Harper D: Complete genome sequence of the model actinomycete Streptomyces coelicolor A3(2). Nature 2002, 417:141-147.

48. Nierman WC, DeShazer D, Kim HS, Tettelin H, Nelson KE, Feldblyum T, Ulrich RL, Ronning CM, Brinkac LM, Daugherty SC: Structural flexibility in the Burkholderia mallei genome. Proc Natl Acad Sci USA 2004, 101:14246-14251.

49. Tumapa S, Holden MT, Vesaratchavest M, Wuthiekanun V, Limmathurotsakul D, Chierakul W, Feil EJ, Currie BJ, Day NP, Nierman WC, Peacock SJ: Burkholderia pseudomallei genome plasticity associated with genomic island variation. BMC Genomics 2008, 9:190.

50. Winsor GL, Khaira B, Van Rossum T, Lo R, Whiteside MD, Brinkman FS: The Burkholderia Genome Database: facilitating flexible queries and comparative analyses. Bioinformatics 2008, 24:2803-2804.

51. Okeley NM, Paul M, Stasser JP, Blackburn N, Donk WA van der: SpaC and $\mathrm{NisC}$, the cyclases involved in subtilin and nisin biosynthesis, are zinc proteins. Biochemistry 2003, 42:13613-13624.

52. Welsh EA, Liberton M, Stockel J, Loh T, Elvitigala T, Wang C, Wollam A, Fulton RS, Clifton SW, Jacobs JM: The genome of Cyanothece 51142, a unicellular diazotrophic cyanobacterium important in the marine nitrogen cycle. Proc Natl Acad Sci USA 2008, 105:15094-15099.

53. Crooks GE, Hon G, Chandonia JM, Brenner SE: WebLogo: a sequence logo generator. Genome Res 2004, 14:1188-1190.

54. Heng NCK, Tagg JR: What's in a name? Class distinction for bacteriocins. Nat Rev Microbiol 2006, 4:160.

55. Sablon E, Contreras B, Vandamme E: Antimicrobial peptides of lactic acid bacteria: mode of action, genetics and biosynthesis. Adv Biochem Eng Biotechnol 2000, 68:21-60.

56. Patton GC, Paul M, Cooper LE, Chatterjee C, Donk WA van der: The importance of the leader sequence for directing lanthionine formation in lacticin 481. Biochemistry 2008, 47:7342-7351.

57. Tanabe $Y$, Kaya K, Watanabe MM: Evidence for recombination in the microcystin synthetase (mcy) genes of toxic cyanobacteria Microcystis spp. J Mol Evol 2004, 58:633-641.

58. Li B, Sher D, Kelly L, Huang K, Joewono I, Rusch D, Chisholm SW, Donk WA van der: Natural combinatorial biosynthesis of secondary metabolites 
in planktonic marine cyanobacteria. Proc Natl Acad Sci USA 2010 in press.

59. Haft DH, Loftus BJ, Richardson DL, Yang F, Eisen JA, Paulsen IT, White O: TIGRFAMs: a protein family resource for the functional identification of proteins. Nucleic Acids Res 2001, 29:41-43.

60. Selengut JD, Haft DH, Davidsen T, Ganapathy A, Gwinn-Giglio M, Nelson WC, Richter AR, White O: TIGRFAMs and genome properties: tools for the assignment of molecular function and biological process in prokaryotic genomes. Nucleic Acids Res 2007, 35:D260-264.

61. Finn RD, Mistry J, Tate J, Coggill P, Heger A, Pollington JE, Gavin OL, Gunasekaran P, Ceric G, Forslund K: The Pfam protein families database. Nucleic Acids Res 2010, 38:D211-222.

62. Altschul SF, Madden TL, Schaffer AA, Zhang J, Zhang Z, Miller W, Lipman DJ: Gapped BLAST and PSI-BLAST: a new generation of protein database search programs. Nucleic Acids Res 1997, 25:3389-3402.

63. Duda DM, Walden H, Sfondouris J, Schulman BA: Structural analysis of Escherichia coli ThiF. J Mol Biol 2005, 349:774-786.

64. Lehmann C, Begley TP, Ealick SE: Structure of the Escherichia coli ThiSThif complex, a key component of the sulfur transfer system in thiamin biosynthesis. Biochemistry 2006, 45:11-19.

65. Lake MW, Wuebbens MM, Rajagopalan KV, Schindelin H: Mechanism of ubiquitin activation revealed by the structure of a bacterial MoeBMoaD complex. Nature 2001, 414:325-329.

66. Gonzalez-Pastor JE, Millan San JL, Castilla MA, Moreno F: Structure and organization of plasmid genes required to produce the translation inhibitor microcin C7. J Bacteriol 1995, 177:7131-7140.

67. Roush RF, Nolan EM, Lohr F, Walsh CT: Maturation of an Escherichia coli ribosomal peptide antibiotic by ATP-consuming N-P bond formation in microcin C7. J Am Chem Soc 2008, 130:3603-3609.

68. Regni CA, Roush RF, Miller DJ, Nourse A, Walsh CT, Schulman BA: How the MccB bacterial ancestor of ubiquitin $\mathrm{E} 1$ initiates biosynthesis of the microcin C7 antibiotic. EMBO J 2009, 28:1953-1964.

doi: $10.1186 / 1741-7007-8-70$

Cite this article as: Haft et al., Expansion of ribosomally produced natural products: a nitrile hydratase- and Nif1 1-related precursor family BMC Biology 2010, 8:70

Submit your next manuscript to BioMed Central and take full advantage of:

- Convenient online submission

- Thorough peer review

- No space constraints or color figure charges

- Immediate publication on acceptance

- Inclusion in PubMed, CAS, Scopus and Google Scholar

- Research which is freely available for redistribution

Submit your manuscript at www.biomedcentral.com/submit
C BioMed Central 